\title{
Experiências agroecológicas no IFMT - campus Barra do Garças ${ }^{1}$
}

\author{
Agroecological experiences at the IFMT - Barra do Garças campus \\ Daisy Rickli Binde ${ }^{2 *}$, Flávia Tavares Couto Fabian², Tassiana Reis Rodrigues dos Santos², \\ Tamires Rodrigues Monteiro ${ }^{2}$
}

\begin{abstract}
RESUMO
O presente trabalho objetiva apresentar as experiências vividas no Instituto Federal de Educação, Ciência e Tecnologia de Mato Grosso, campus Barra do Garças, no ano de 2019 e 2020 no âmbito da Agroecologia. As práticas aqui apresentadas tiveram como meta prioritária contrapor os modelos de agricultura convencional, para construção de novos paradigmas que visam a preservação do meio ambiente e valorizem o ser humano. Portanto, serão apresentados os projetos desenvolvidos: Horta Agroflorestal Sucessional, Projeto Compostar, Criação de peixes em caixas d'água, I e II Campeonatos de Coleta de Sementes Muvuquinha do Cerrado e Avicultura sustentável para produção de ovos semicaipira. Os projetos tiveram cunho de pesquisa, ensino e extensão e trazem em sua estrutura a importância e funcionalidade da agrofloresta, que se relaciona com a biodiversidade, com a ciclagem de nutrientes, e com a criação de animais. As ações colaboraram no movimento da agroecologia, em um processo de construção coletiva de conhecimento.
\end{abstract}

Palavras-chave: Educação; Agroecologia; Sustentabilidade.

\begin{abstract}
This paper aims to present the experiences lived at the Federal Institute of Education, Science and Technology of Mato Grosso, Barra do Garças campus, in the year 2019 and 2020 in the context of Agroecology. The practices presented here had as a priority goal to oppose the models of conventional agriculture, for the construction of new paradigms that aim to preserve the environment and value the human being. Therefore, the developed projects will be presented: Successional Agroforestry Garden, Compostar Project, Breeding Fish in Water Tanks, I and II Muvuquinha do Cerrado Seed Collection Championships and Sustainable Poultry for the production of semi-caipira eggs. The projects had a research, teaching and extension nature and brought in their structure the importance and functionality of agroforestry, which is related to biodiversity, nutrient cycling, and animal husbandry. The actions collaborated in the agroecology movement, in a process of collective construction of knowledge.
\end{abstract}

Keywords: Education; Agroecology; Sustainability.

\footnotetext{
${ }^{1}$ Trabalho realizado com financiamento do Conselho Nacional de Desenvolvimento Científico e Tecnológico (CNPq) pela Chamada MCTIC/MAPA/MEC/SEAD - Casa Civil/CNPq $\mathrm{N}^{\circ}$ 21/2016.

${ }^{2}$ Instituto Federal de Educação, Ciência e Tecnologia de Mato Grosso IFMT Campus Barra do Garças 1.*E-mail: daisyrickli@gmail.com
} 


\section{INTRODUÇÃO}

Na história, a agricultura de base ecológica foi a primeira e principal forma de produção por um longo período, mas com o avanço das tecnologias ela foi substituída pela agricultura convencional que utiliza produtos químicos e insumos que contaminam o solo e a água. Essas atividades agridem o meio ambiente e também acarretam a homogeneização da agricultura mundial. As práticas não ecológicas provocaram efeitos nocivos ao meio ambiente, o que traz questionamentos em relação a continuação da prática de agricultura moderna (BORSATO, 2015). Os modelos convencionais são caracterizados principalmente pelas arações e gradagens, que ocasionam degradação do solo, pela erosão, perda da qualidade estrutural e consequente compactação (MARX; et al., 2017). Portanto, os modelos de cultivo que priorizam o monocultivo e usam o revolvimento são considerados insustentáveis.

A modernidade trouxe grandes mudanças para a sociedade e para a agricultura, sendo o capitalismo a principal base econômica, no qual se busca lucro imediato e acúmulo de capital. Esse novo cenário trouxe grandes dificuldades para os pequenos agricultores, como a desvalorização de sua mão de obra, fome, pobreza, desigualdade social, entre outras. Dessa forma, é necessário o resgate da agricultura tradicional e a agroecologia de base ecológica é uma ferramenta necessária para a preservação de práticas agrícolas e saberes dos povos tradicionais. Nesse sentido, é de suma importância a integração entre os saberes dos agricultores com as pesquisas desenvolvidas em centros universitários. E o processo de modernização é importante para a evolução como sociedade, mas não deve deixar de lado o desenvolvimento social, ambiental, econômico e rural (ENDERLE, et al., 2015).

A ideia de produção agrícola ecológica se espalhou por diversos países com diferentes denominações, porém, com um conceito coletivo - a filosofia de uma agricultura natural integrada com o ambiente. Portanto houve um aumento da adoção dos métodos ecológicos, onde os agricultores desenvolveram formas de reconfigurar o modelo de agricultura convencional e esses se tornaram menos dependentes de combustíveis fósseis. Dessa forma tais práticas se configuram na possibilidade de acesso econômico e contribuem para promoção da saúde humana (BORSATO, 2015).

$\mathrm{Na}$ década de 70 iniciou-se a normatização das práticas sustentáveis e ecológicas

e em 1983 surgiu a expressão desenvolvimento sustentável, através do Relatório 
Brudtland. O principal anúncio da Conferência ECO-92 visou a diminuição de práticas nocivas ao meio ambiente e portanto, maior adoção de produtos orgânicos. A primeira normatização em que conceituou os métodos para a reconstrução da agricultura moderna, visou excluir a utilização de agrotóxicos, a diminuição da exploração de recursos naturais não renováveis e adequação de suas formas de uso, buscando desta forma a preservação do meio ambiente (BORSATO, 2015).

Nesse contexto surge a agroecologia como ciência que atende a complexidade de fatores: econômicos, sociais, tecnológicos e sustentáveis, que visam a relação entre o meio ambiente e o ser humano sem formas de prejuízo para ambos. Dessa forma, essa ciência busca a transição dos modelos convencionais para um modelo de agricultura que incorpore princípios e tecnologias de base ecológica. De forma geral, a agroecologia busca um processo de transformação da agricultura no decorrer do tempo, sempre com enfoque no desenvolvimento rural sustentável, "que considere as seis dimensões: econômica, social, cultural, política, ética e ecológica" (CAPORAL, 2004, p.19).

Em 2003 e 2007, foram regulamentadas leis que objetivaram a conservação da biodiversidade ecológica, recomposição dos produtos retirados do meio ambiente e definição de produto orgânico. Portanto, o produto orgânico é definido como aquele que foi extraído do meio ambiente sem causar danos ao mesmo, podendo ser comercializado apenas com certificação. Com ressalva para os comercializados diretamente por agricultores familiares, que foram protegidos por certificação facultativa e também foi regulamentado o seguro da boa qualidade do produto para o consumidor. Quanto mais os agricultores aprendem sobre os métodos de produção orgânica e compartilham, maiores são as possibilidades de conversão agroecológica e maior o aumento de geração de trabalho e renda dos agricultores familiares (BORSATO, 2015).

A agroecologia é uma ciência que emprega conhecimentos diversos para análises e proposições com finalidade de que a agricultura seja sustentável e o agroecossistema é a unidade de estudos da agroecologia com enfoque ecológico (BORSATO, 2015). Nesse sentido, a agrofloresta é um sistema de produção orgânica, que reproduz a dinâmica de uma floresta natural. O sistema consiste no cultivo de uma diversidade de plantas para a produção de uma variedade de frutos, folhas medicinais, roça, horta, madeira, entre outras e ainda pode ser uma forma de criar animais. Essa diversidade faz com que uma relação entre as espécies se forme, onde os nutrientes produzidos por uma espécie auxiliem o desenvolvimento de outras e consequentemente 
melhore a nutrição animal. "Esta diversidade também é a responsável por um melhor aproveitamento da energia do sol, da água da chuva e dos nutrientes do solo" (LONGHI; PINTO, 2005, p. 16).

Diante das possibilidades da agroecologia como forma de produção agrícola é importante construir espaços para difundir e desenvolver essas técnicas no ambiente escolar. Portanto, o enfoque deve estar relacionado na equalização entre a agricultura moderna e no resgate da agricultura tradicional, para que os agricultores tenham condições de realizar uma produção limpa, que não traga prejuízo ao meio ambiente e gere lucros. Dessa forma a comunidade escolar pode colaborar no processo de desenvolvimento da agroecologia e na busca de uma sociedade mais justa.

Nesse contexto, esse trabalho tem como objetivo relatar e divulgar as experiências agroecológicas desenvolvidas no Instituto Federal de Educação, Ciência e Tecnologia de Mato Grosso, campus Barra do Garças (IFMT/BAG) nos anos de 2019 e 2020 em parceria com o Núcleo de Estudo em Agroecologia e Produção Orgânica Vale do Araguaia (NEA-VA). Dessa forma, trará em sua estrutura a importância e funcionalidade da agrofloresta, que está relacionada com a ciclagem de nutrientes, com a biodiversidade e com a criação de animais. Portanto, será abordada a relevância da agroecologia para o desenvolvimento sustentável urbano e rural.

\section{METODOLOGIA}

Para construção do relato das seguintes atividades: horta agroflorestal sucessional, projeto compostar, criação de peixes em caixas d'água, primeiro e segundo campeonatos de coleta de sementes "Muvuquinha do Cerrado" e avicultura sustentável para produção de ovos semi-caipira, elaborou-se um questionário qualitativo no “Google Forms". Assim, para o desenvolvimento do estudo a metodologia utilizada caracterizou-se como pesquisa descritiva segundo Gil (1999) e quanto à natureza da pesquisa ela foi qualitativa numa abordagem que trabalha os dados buscando seu significado como base para percepção dos acontecimentos dentro do seu contexto (TRIVIÑOS, 1987).

O questionário abordou questões acerca do período em que ocorreram as atividades agroecológicas, assim como, os princípios utilizados, a maneira como foram desenvolvidas, a relação entre as atividades, participação dos estudantes, os resultados 
obtidos e também as principais dificuldades encontradas pelos docentes responsáveis por cada atividade.

\section{RESULTADOS E DISCUSSÃO}

A descrição das atividades realizadas foi desenvolvida segundo o material fornecido pelo responsável de cada segmento no questionário qualitativo no "Google Forms". Os resultados apontam as potencialidades e os desafios em uma análise crítica. Tais considerações trouxeram, em sua análise, um espelho das atividades para que os projetos avancem.

\subsection{Horta agroflorestal sucessional}

A implantação da horta ocorreu em dois dias consecutivos no fim do mês de Maio de 2019 durante o Curso promovido pelo Núcleo de Estudos em Agroecologia do Vale do Araguaia (NEA-VA). Primeiramente foi transmitido aos alunos e participantes do curso conceitos sobre o tema e posteriormente a parte prática da implantação da horta que foi: preparo do solo, levantamento dos canteiros e plantio das espécies.

Os princípios agroecológicos utilizados foram primeiramente a produção com o mínimo de impacto possível ao meio ambiente, ou seja de forma sustentável. Em relação aos conceitos sobre agrofloresta sucessional, foram adotados os princípios de sucessão ecológica, elevada biodiversidade de espécies e estratificação. Essa atividade pode estar relacionada com a dieta alimentar das aves. Assim como o aproveitamento da água dos criatórios de peixes para irrigação da horta e também com a utilização das mudas produzidas no viveiro.

Nesse processo os estudantes foram primordiais tanto na implantação, mas principalmente na manutenção e manejo da horta. Segundo a docente responsável,

\footnotetext{
"a experiência foi enriquecedora no sentido de aprenderem um novo conceito de produção, mas também foi importantíssima nos quesitos de responsabilidade, engajamento, autonomia, troca de experiências e dúvidas, mas principalmente os alunos foram inseridos e acredito que desenvolveram o sentimento de pertencimento durante o tempo que participaram do processo".
}

Os resultados obtidos foram positivos, a produção foi satisfatória e houve o engajamento dos alunos durante o desenvolvimento das atividades. Além de ser um ambiente produtivo, foi um local de aprendizagem, onde diversos professores usaram a 
horta para aulas em suas disciplinas. Foi possível a disseminação do conhecimento sobre a agrofloresta sucessional para a comunidade acadêmica, assim como para a comunidade externa por meio de várias atividades desenvolvidas no Campus e fora dele, como a Feira Agroecológica, a qual os produtos oriundos da horta foram comercializados. A maior dificuldade, no ponto de vista do responsável, foi a mão de obra durante o período de férias para a realização das atividades necessárias.

\subsection{Projeto compostar}

O projeto foi iniciado no segundo semestre de 2019 e teve como objetivo a implantação de um pátio de compostagem para adequação de uma metodologia para a região e disseminação da técnica por meio de atividades extensionistas. O princípio teórico foi baseado no método UFSC, referência do Ministério do Meio Ambiente para compostagem em pátios de pequeno porte, realizada em leiras estáticas com aeração passiva.

A principal justificativa fundamenta-se no grande volume de resíduos gerados no meio urbano que podem ser convertidos em adubo para serem usados em quintais, hortas, vasos, jardinagem urbana e outros. A parcela compostável equivale a 51,4 \% do total gerado, o que corresponde a aproximadamente 70 toneladas em Barra do Garças (SVERSUT, 2019). No entanto, a falta de gestão de resíduos sólidos urbanos em Barra do Garças não permite o aproveitamento desses materiais e ainda representam sérios problemas ambientais e sociais.

Na medida que o uso da compostagem é disseminado, novos horizontes são abertos, o que representa novas formas de geração de renda, manutenção dos ciclos biogeoquímicos e maior sustentabilidade no meio urbano. Dessa forma, a compostagem é uma ferramenta da agroecologia e a técnica usada no campus - UFSC - apresentou-se muito eficiente na degradação de resíduos. Foi possível obter um substrato orgânico que pode ser usado na horta, no viveiro para produção de mudas e também pode ser utilizado para tratar os resíduos gerados no aviário.

A participação dos estudantes foi essencial na execução das atividades. Durante o projeto os alunos puderam constatar na prática que o processo é totalmente eficiente, não gera odores desagradáveis, não atrai animais e ainda gera um produto de valor econômico. Segundo Valente, et al. (2009), a eficiência da compostagem está diretamente relacionada com a relação entre os fatores físico-químicos e as 
características particulares da fração orgânica, portanto, se bem manejadas apresentam ótimas condições de decomposição. Portanto, pode-se concluir que a execução da técnica de compostagem foi gerida com muita eficiência.

Essa atividade ofereceu um número expressivo de oficinas, proporcionou a participação da comunidade externa e interna e teve a participação de estagiários e bolsistas, portanto, teve relevância positiva como mecanismo de educação ambiental e multiplicação da técnica.

A principal dificuldade desta atividade foi o período de chuvas que lavou um pouco o material e também a falta de manutenção da limpeza do local. Porém recentemente, foi implementado uma cobertura para pátio via ação voluntária entre os servidores do campus e material adquirido com recursos do CNPq. Com a adequação do espaço físico tem-se uma vitrine para multiplicação da ação em outros espaços. Porém, é necessário que ações centralizadas sejam estimuladas, ações essas geridas pelo município e necessitam de uma usina de triagem, sendo necessário estudo de impacto e licença ambiental. No entanto, é importante destacar para discussões futuras o observado por Siqueira e Assad (2015, p.257) em um estudo realizado no estado de São Paulo:

"A partir do levantamento realizado, pode-se verificar que é possível e necessário - diversificar a gestão de resíduos nos municípios. Sistemas centralizados são mais falíveis $(82 \%$ experiências identificadas foram encerradas) que descentralizados por serem onerosos e produzirem um composto que frequentemente mais se aparenta com um resíduo que com um produto."

As unidades descentralizadas são as experiências desenvolvidas pela comunidade, seja ela comunitária, domiciliar ou institucional. Portanto configuram-se como iniciativas importantes e necessitam ser estimuladas, assim como o poder público deve ser cobrado por suas competências legais. Segundo a Política Nacional de Resíduos Sólidos - lei 12.305/10 (BRASIL, 2010), cuja premissa é a redução de Resíduos Sólidos, portanto prevê que somente rejeitos estariam sendo destinados aos aterros e aloca o município como responsável pela mediação entre a geração e destinação do resíduos sólidos urbanos. Nesse sentido destaca-se a importância da relação escola e poder público para continuidade de ações e mudanças substanciais na sociedade. Assim, a seguinte afirmativa é relevante:

"O pátio de compostagem com área aproximada de $35 \mathrm{~m} 2$, foi capaz de fazer o tratamento de cerca de 3 (três) $\mathrm{T}$ (toneladas) de RSU provenientes de supermercados e mais $14 \mathrm{~m}^{3}$ de resíduos de 
jardinagem, limpeza urbana e serragem em 3 (três) meses. Diante do exposto fica evidente a capacidade de tratamento de um pequeno espaço, o que injustifica a existência de lixões a céu aberto" (YAMAUCHI; BINDE; SACCO, 2021, p.92).

\subsection{Criação de peixes em caixas d'água}

Ocorreu em setembro de 2019, através do NEA-VA e teve como base os princípios de produção animal aliada ao aproveitamento sustentável da água e utilização de alimentação alternativa - farinha de inseto. Como ponto em comum às demais atividades houve a utilização de práticas sustentáveis. As práticas aliadas ao ensino despertam curiosidade e interesse dos alunos, porém, a participação dos alunos nestas atividades são dificultosas pela extensa carga horária de aulas que já possuem, transtornos relacionados ao transporte e necessidade de trabalho aos finais de semana.

Como resultado ocorreu a substituição de ração comercial por vários níveis de farinha de inseto, porém não se mostrou indicada para a produção de peixes em caixas d'água, pois levou a uma redução nos índices de produtividade avaliados. Vale ressaltar também que algumas das dificuldades encontradas foram: dificuldade no acesso, presença de animais peçonhentos, ausência de controle de entrada de pessoas, escassa mão de obra e falta de infraestrutura.

\subsection{I e II Campeonatos de coleta de sementes muvuquinha do Cerrado}

Foram realizados dois campeonatos: um em 2019 e outro em 2020. Em 2019 o campeonato ocorreu no mês de setembro e foi implantado/desenvolvido a partir da divulgação nas salas de aula e por meio de material impresso nos murais da escola. Em 2020 o campeonato ocorreu no mês de outubro e foi implantado e desenvolvido totalmente de forma remota devido às restrições impostas pela pandemia. A divulgação, bem como a disponibilização das informações, foram exclusivamente realizadas pelas redes sociais.

Nessas edições não só alunos, mas também servidores puderam participar tendo como finalidade a conservação e ampliação da biodiversidade dos ecossistemas, em especial do bioma Cerrado. Essas atividades estão interligadas com as outras demais na medida em que houve a construção de um banco de sementes. Esse banco pode ser usado no enriquecimento da horta agroflorestal sucessional, para produção de mudas no viveiro do campus e para recuperação de áreas degradadas através de muvuca ou plantio de mudas. 
Em relação a participação dos estudantes, deve-se dizer que quantitativamente a participação ainda ficou aquém do ideal. No entanto, em relação àqueles que participaram foi possível observar que se sentiram estimulados a identificar as espécies arbóreas do bioma onde vivem, conhecendo sua morfologia, diversidade genética, áreas de coleta, tipos de frutos, flores e sementes, polinização e dispersão. E ainda, a atividade promoveu a integração, o espírito participativo e a cooperação, assim como estimulou o desenvolvimento de valores relacionados à sustentabilidade dos ecossistemas. Como resultado, em 2019 coletou-se aproximadamente $65 \mathrm{~kg}$ de sementes diversificadas em mais de 44 espécies da flora do Cerrado. E as principais dificuldades encontradas foram a mobilização e engajamento dos alunos nas atividades e as limitações impostas pela pandemia no ano de 2020.

\subsection{Avicultura sustentável para produção de ovos semi-caipira}

A prática de avicultura no IFMT/BAG começou no final de dezembro de 2016 e início de 2017, com a doação de 9 aves para o campus. Buscou-se a substituição parcial da alimentação das aves por produtos livres de agrotóxicos, transgênicos, a integração da avicultura com outras atividades, sempre visando o bem-estar das aves.

A avicultura relaciona-se com as demais práticas do campus pois proporciona matéria prima para compostagem, onde a cama do aviário deve ser tratada e o composto obtido pode ser utilizado na horta agroecológica e também os restos dos vegetais produzidos na horta podem ser utilizados na alimentação das aves.

A participação dos alunos no geral foi positiva, houve dedicação e interesse pelo setor da avicultura, principalmente pela melhoria das instalações utilizadas para este fim. Eles puderam aprender sobre manejo das aves, sobre tecnologia de produtos de origem animal e modelos alternativos. Tudo isto, de forma descontraída e que proporcionava aos alunos prazer em fazer parte do processo de criação das aves.

Como resultado foram produzidos mais de 1000 ovos semi-caipira. Muitos alunos dos Cursos Técnico em Controle Ambiental e Alimentos fizeram estágio no setor, como requisito para desenvolvimento de Trabalho de Conclusão de Curso. Também foram produzidos dois resumos simples na VI Jornada Científica, e um dos resumos foi premiado e vários alunos participaram de atividades de iniciação científica. Foi produzido um artigo científico a partir de relatos de experiência no setor. A avicultura recebeu visitas técnicas de vários alunos dos cursos de Zootecnia e Medicina 
Veterinária do Centro Universitário - UNIVAR. Alunos dos cursos de Pós-Graduação em Agroecologia e do curso de Avicultor puderam desenvolver atividades práticas no setor.

Um grande obstáculo foi o destino dos ovos, que devido ao grande volume produzido, não foram totalmente utilizados nas atividades práticas e, assim, muitos foram perdidos. Também foi dificultosa a conciliação de tarefas rotineiras burocráticas durante jornada de trabalho no IFMT, com as atividades na avicultura que muitas vezes são bem trabalhosas. Não foi possível desenvolver o projeto de avaliação do desempenho de aves utilizando ração desenvolvida dentro do projeto, necessitando de prorrogação.

\subsection{Conexões, análises e desafios}

Ao se discutir sobre o valor da escola como ambiente de práticas e vivências, Altieri e Nicholls (2021) relatam que estratégias de difusão ecopedagógicas sobre modelos agroecológicos são importantes para a restauração e fortalecimento das atividades produtivas, assim como a difusão e experimentação relacionados aos modelos agroecológicos. Nessa perspectiva, destaca-se a ampliação dos espaços escolares por meio de projetos como mecanismo alternativo de aprendizagem. Os benefícios gerados são positivos para o ambiente escolar e para a sociedade.

Apesar de as atividades agroecológicas desempenharem papel importante na formação de alunos, ainda existem grandes desafios com relação a sua introdução em instituições de ensino, principalmente em escolas de nível básico. A falta de infraestrutura e mão de obra escassas foram os aspectos que ficaram evidentes nas respostas dos responsáveis, quando expuseram as dificuldades encontradas com a execução das atividades. Desafios parecidos foram identificados no trabalho de Silva \& Souza (2015) em duas escolas da rede estadual de ensino do Paraná, no qual a falta de apoio institucional, carência de recursos financeiros para aquisição de materiais necessários para criação e manutenção de horta orgânica e composteira, foram grandes gargalos. Além disso, falta de engajamento dos envolvidos, problemas com mão de obra em período de férias foram dificuldades citadas por Vieira (2017) em seu estudo com experiências agroecológicas em escolas itinerantes de assentamentos do MST no Paraná. 
Cabe ressaltar que no presente estudo, todas as atividades agroecológicas foram desenvolvidas via NEA-VA, porém, apesar de contar com recursos financeiros, esses não foram suficientes para contratação de técnico para a manutenção das atividades e demandas oriundas de cada projeto por um longo período. Dentre os desafios citados por Souza et al. (2017) com base nos relatórios de atividades dos NEAs os valores das bolsas de extensão ficam aquém dos valores de mercado e inviabilizam a contratação de profissionais com a experiência necessária para contribuir com o desenvolvimento das atividades. Nesse sentido, o apoio institucional é primordial tanto em infraestrutura quanto em mão de obra para o bom andamento e desempenho de projetos relacionados à agroecologia que tanto contribuem para o ensino, pesquisa e extensão.

Outro desafio a ser alcançado em ações futuras, é a integração entre as atividades conforme observado pelos responsáveis de cada segmento. Nesse sentido, concerne a observação de Caporal e Costabeber (2002) sobre a agroecologia, quando dizem que o enfoque é no fornecimento de técnicas que proporcionem formas de produção com princípio baseado no entendimento da natureza com abordagem científica. Portanto, essa ciência analisa os agrossistemas e suas interações, de modo a valorizar a diversidade. Segundo Gliessman (2000), esse enfoque proporciona a manutenção da qualidade produtiva do solo, assim pode fornecer alimentos em períodos mais extensos. Essa lógica contraria os sistemas convencionais que esgotam os recursos naturais, porque a base ecológica dos sistemas agroecológicos favorecem o balanço energético e preservam a biodiversidade (VARGAS; FONTOURA; WIZNIEWSKY, 2013).

\section{CONSIDERAÇÕES FINAIS}

Tendo em vista os resultados levantados e as discussões realizadas, é notório a integração da pesquisa, do ensino e da extensão. Foi possível observar que os estudantes foram atuantes em todas as etapas desenvolvidas e isso proporcionou um espaço de ensino pela vivência e por meio de aulas práticas interdisciplinares e multidisciplinares, bem como, subsidiou oportunidade de transformação social. Ressalta-se também as articulações externas à instituição através das ações de extensão, que colaboraram com o movimento do objeto de estudo, aqui sendo a agroecologia. Tanto a comunidade interna como a externa foram motivadas, devido ao envolvimento dos participantes e 
por levarem suas experiências para outros espaços, num processo de construção coletiva de conhecimento.

Os caminhos na construção do enfoque agroecológico e na busca de uma transição de ações que geram grandes impactos ambientais para moldes mais sustentáveis, ainda estão a passos lentos. Todavia, são grandes as perspectivas de integrar as atividades desenvolvidas no presente estudo. Sendo assim, tendo como referência os acertos e ganhos das práticas realizadas é salutar avançar com os projetos para colaborar com o desenvolvimento da agroecologia na região do Vale do Araguaia, pois essa é uma importante estratégia para o desenvolvimento sustentável urbano e rural.

\section{REFERÊNCIAS}

ALTIERI, M. A.; NICHOLLS, C. I. Do modelo agroquímico à agroecologia: a busca por sistemas alimentares saudáveis e resilientes em tempos de COVID - 19. Edição especial - Agronegócio em tempos de colapso planetário: abordagens críticas. Vol. 57, p. 245-257, jun. 2021.

BORSATO, A. V. Sistema de Produção Agrícola de Base Ecológica. Brasília: Embrapa Pantanal, 2015.

BRASIL. Lei ${ }^{\circ} 12.305$, de 2 de agosto de 2010. Institui a Política Nacional de Resíduos Sólidos. Disponível em: http://www.planalto.gov.br/ccivil_03/_ato2007-2010/ 2010/lei/112305.htm. Acesso em: 10 ago. 2021.

CAPORAL, F. R; COSTABEBER, J. A. Agroecologia enfoque científico e estratégico para apoiar o desenvolvimento rural sustentável. Porto Alegre: EMATER/RS-ASCAR, 2002.

CAPORAL, F. R; COSTABEBER, J. A. Agroecologia: alguns conceitos e princípios. São Paulo: MDA/SAF/DATER-IICA Brasília, 2004.

ENDERLE, A. T.; FARINA, V. A.; LIMA, J. A de; OLIVEIRA, O. J. F de. A agroecologia como alternativa para o resgate do saber popular: limites e desafios. In: III Jornada Questão Agrária e Desenvolvimento, 2015, Laranjeiras do Sul. Disponível em: <http://www.jornadaquestaoagraria.ufpr.br/wp-content/uploads/2016/04/VolmirAt\%C3\%ADlio-Farina-Armando-Triches-Enderle-Julaino-Antunes-de-Lima-OdairJos\%C3\%A9-Ferrira-de-Oliveira.pdf> . Acesso em: 20 de abril de 2021.

GIL, A. C. Métodos e técnicas de pesquisa social. 5.ed. São Paulo: Atlas, 1999.

GLIESSMAN, S. R. Agroecologia: processos ecológicos em agricultura sustentável. Porto Alegre: Editora da Universidade - UFRGS, 2000. 
LONGHI, A.; PINTO, R. A. DA S. Sistemas agroflorestais e os sabores da floresta. Passo Fundo: Centro de Tecnologias Alternativas Populares. 2005.

MARX, L. B.; RENTZ, J. C. L.; BULEGON, S.; BALBINOT, M.; MUHL, F. R.; FELDMANN, N. A.; RHODEN, A. C. Sistemas de cultivo. In.: $4^{\circ}$ AGROTEC Simpósio de Agronomia e Tecnologia em Alimentos, 2017. Disponível em: < https://eventos.uceff. edu.br/site/4-simposio-de-agronomia-e-tecnologia-em-alimentos>. Acesso em: 12 de out de 2021.

SILVA, C. C. C.; SOUZA, M. A. A. Limites e Potencialidades da Agroecologia na Educação. In: III Jornada. Questão agrária e desenvolvimento, os sujeitos na soberania alimentar. 2015.

SIQUEIRA, T. M. O. de; ASSAD, M. L. R. C. L. Compostagem de resíduos sólidos urbanos no Estado de São Paulo (Brasil). Ambiente \& Sociedade, São Paulo, v. 18, n.4, p. 243-264, 2015.

SOUZA, N. A.; et al Os núcleos de agroecologia: caminhos e desafios na indissociabilidade entre ensino, pesquisa e extensão. In: SAMBUICHI, R. H. R.; et al (Ed.). A política nacional de agroecologia e produção orgânica no Brasil: uma trajetória de luta pelo desenvolvimento rural sustentável. Brasília: Ipea,. pag. 403 a 431. 2017.

SVERSUT, A. MPE aciona prefeito e ex-prefeito por irregularidades no aterro sanitário MPMT, 05 ago. 2019. Notícias. Disponível em:

https://mpmt.mp.br/conteudo/58/53830/ mpe-aciona-prefeito-e-ex-prefeito-porirregularidades-no-aterro-sanitario. Acesso em: 23 ago. 2021.

TRIVIÑOS, A. N. S. Introdução à pesquisa em Ciências Sociais: a pesquisa qualitativa em Educação. São Paulo: Editora Atlas, 1987.

VALENTE, B. S.; XAVIER, E. G.; MORSELLI, T. B. G. A., JAHNKE, D. S.; BRUM JR., B. DE S.; CABRERA, B.R.; MORAES, P. DE O.; LOPES, D.C.N. Fatores que afetam o desenvolvimento da compostagem de resíduos orgânicos. Archivos de Zootecnia: 58, 59-85. 2009.

VARGAS, D. L.; FONTOURA, A. F.; WIZNIEWSKY, J. G. Agroecologia: base da sustentabilidade dos agroecossistemas. Geografia Ensino \& Pesquisa, v. 17, n. 1, 2013.

VIEIRA, T. C. L. Experiências de educação em agroecologia em escolas itinerantes e de assentamento vinculadas ao MST no Paraná: a função social da escola na construção da agroecologia. Olhar de Professor, v. 20, n. 2, p. 321-343, 2017. 
YAMAUCHI, T. E.; BINDE, D. R.; SACCO, A. P. Compostar: uma proposta para a destinação da fração orgânica dos resíduos sólidos urbanos gerados em Barra do Garças - MT. Revista Panorâmica: Edição Especial, v.2, 2021.

Recebido em: 01/10/2021

Aprovado em: 30/10/2021

Publicado em: 10/11/2021 